\title{
An Empirical Investigation of the Relationship Between Financial Measures and Corporate Social Responsibility
}

\author{
Yu-Min Lian ${ }^{1}$, Yi-Ching Chen ${ }^{2}$, Bing-Kai Kao ${ }^{2}$, Yung-Hsin Yeh ${ }^{1}$ \\ ${ }^{1}$ Department of Business Administration, Fu Jen Catholic University, No. 510, Zhongzheng Rd., Xinzhuang Dist., New Taipei City 24205, Taiwan \\ ${ }^{2}$ Department of Accounting, Fu Jen Catholic University, No. 510, Zhongzheng Rd., Xinzhuang Dist., New Taipei City 24205, Taiwan \\ Corresponding author. Tel.: +8862 29052989; fax: +886229089219. \\ E-mail addresses: 140476@mail.fju.edu.tw (Y.-M. Lian), 95352506@nccu.edu.tw (Y.-M. Lian)
}

Abstract: Nowadays, corporate social responsibility (CSR) occupies an important place in doing business worldwide. The public commonly perceives CSR as necessary for businesses to improve the well-being of society. De facto, it is difficult to find a specific definition of CSR. The purpose of this study is to investigate whether CSR has a significant relationship with organizational financial performance in terms of earnings per share (EPS) and the annual rates of return rate (RETURN) on individual stocks in Taiwan. In this study, we use a multi-factor regression model to examine corporate value. The data is taken from the Taiwan Economic Journal (TEJ) database. The empirical results show that: (1) The growth rate of sales (SGR) has a positive impact on RETURN; (2) CSR and leverage (LEV) are significantly correlated with EPS; (3) SGR and return on equity (ROE) have a significant relationship with RETURN; (4) CSR and ROE have a significant correlation with EPS. Consequently, the EPS of the companies that implement CSRs are better than those that do not implement CSRs. However, the results do not indicate that the RETURN of the companies that implement CSRs are better than those that do not implement CSRs.

JEL Classification: C12; C15; C30; C60; G32

Keywords: Financial measure; Corporate social responsibility; Multi-factor regression model; Corporate value

\section{Introduction}

Corporate social responsibility (CSR) is not a fresh concept. Nevertheless, CSR has never been more outstanding on the corporate program than it is today. Though the roots of the concept that we know today as CSR have a long and wide-ranging history, it is mostly a product of the twentieth century, especially from the early 1950s up to the present time. (Archie B. Carroll, 2008) ${ }^{[1]}$ "Unless globalization works for all, it will work for nobody," said the United Nations (UN) Secretary General Kofi Annan on January 31, 1999 at the World Economic Forum (WEF). For the first time, he summoned business representatives from both at home and abroad to become concerned in building up social and environmental foundations to support a new global economy. The goal was to make businesses an integral part of the solution to meet the threats posed by globalization. UN Global Compact was officially launched at the UN Headquarters in New York City on July 26, 2000. The idea behind the UN Global Compact, which includes representatives from the

Copyright (C) 2018 Yu-Min Lian et al.

doi: 10.18282/ff.v7i1.683

This is an open-access article distributed under the terms of the Creative Commons Attribution Unported License

(http://creativecommons.org/licenses/by-nc/4.0/), which permits unrestricted use, distribution, and reproduction in any medium, provided the original work is properly cited. 
environmental principles. (respACT Austria, 2006) ${ }^{[2]}$ A report from the WEF observes that the three key pressures of "corporate competitiveness, corporate governance and corporate citizenship, and the linkages between them, will play a crucial role in shaping the agenda for business leaders. (N. Craig Smith, 2003) ${ }^{[3]}$ It is an important milestone on the road to develop CSR.

CSR has been commonly accepted and valued by corporations, especially the past 50 years. CSR is often related to the idea of "doing good". However, beyond "doing good," corporations also have the responsibility for "avoiding bad" in order to prevent corporate social irresponsibility (CSI), such as cheating customers, violating human rights, or damaging the environment. Thus, CSR entails both "doing good" and "avoiding bad." (Nick Lin-Hi \& Karsten Müller, $2013)^{[4]}$ According to this understanding, corporations assume social responsibility by providing public goods and by enhancing the welfare of stakeholders - those affected by corporate policies and practices. CSR has many different aspects to focus on and therefore will differ from each other. One cannot find a uniform definition of CSR, since it depends on the approach and point of view:

1. The social responsibility of business encompasses the economic, legal, ethical, and discretionary expectations that society has of organizations at a given point in time. (Archie B. Carroll, 2008) ${ }^{[1]}$.

2. A cluster concept which overlaps with such concepts as business ethics, corporate philanthropy, corporate citizenship, sustainability, and environmental responsibility. (Andrew Crane \& Dirk Matten 2007) ${ }^{[5]}$ Researchers still do not have a general agreement on the precise meaning of CSR in these days.

Besides, customers' educational levels have risen for decades. Consumers consider more than quality goods and services when choosing a brand. Many are prioritizing CSR, and holding corporations accountable for effecting social change with their business beliefs, practices and profits. But the most important thing investors and stockholders focus on is still the accomplishment of the business. Do companies engaging in CSRs improve their value or actually reduces their profit? CSR refers to the obligations of the firm to society. Corporations nowadays have to strike the right balance between implementing CSRs and the performance of company. This paper focuses on CSRs and their impacts on corporate value.

The balance of this study is organized as follows: Section 1 introduces the background, incentive and the target of this study. Section 2 reviews the related literatures. Section 3 establishes the research hypotheses and presents the data used in the empirical analysis. Section 4 builds the regression model and performs the empirical analyses. The final Section concludes the outcomes of this study.

\section{Literature review}

CSRs can mean different things for different people depending on how they explain the meaning and whether they stand for. CSRs can be defined as the responsibility that a firm has to its employees, society, and the environment. When corporations are profitable, they need to embrace CSRs by, for example, setting up well and complete regulations of employees' care and pension plans. Along with the gradually growing companies, every single department has focused on their special area to achieve the CSR. Thus, the entire company can pay attention to CSR on a whole level. These CSR actions are based on a lot of theories that show companies assume the direct responsibility to make the society and the world better while they are making profits simultaneously.

The modern but vague concept of CSR arguably began when Howard Bowen (1953) ${ }^{[6]}$ published his seminal book Social Responsibilities of the Businessman, which he inquired "what responsibilities to society may businessmen reasonably be expected to assume". Thus, most of the scholars and the academic theses consider Howard Bowen's theory was the pioneer of CSR. This encourages people and corporations to think about what they can do to society while the companies have gained tremendous profits. However, not only can human rely on governments and organizations to undertake the major responsibilities for social humanity cares and global environmental issues, but corporations can also be a critical portion and role in participating these important and intractable topics. When they start to concern about employees, communities, environment and customers, corporations are on their way to include CSR as one of their visions. Companies have the ability to increase profits while they also can implement CSR in their daily operations. 
Milton Friedman (1969) ${ }^{[7]}$, a famous economist who won the Nobel Prize in the field of Economics, wrote an article of "The social responsibility of business is to increase its profits." on the Times. Moreover, in the book Capitalism and Freedom $(1962)^{[8]}$ that he wrote, "If the corporation makes a contribution, it prevents the individual stockholder from himself deciding how he should dispose of his funds." This argument causes a great debate about the dilemma between gaining maximize profits and paying attention to corporation social responsibility. In modern society, many people are misleading and misunderstanding by the statement that it is immoral for companies to pursue their own profits regardless of business ethics. However, ethics are not conflicted over earning money, instead, they can both be companies' goals simultaneously. In other words, corporations can strike the balance between obtaining profits and achieve social responsibilities. Smith, Richard E (2011) ${ }^{[9]}$ remedies the concept of CSR, which the corporations have taken unbalanced portion on societal norms while generating financial returns, so he defines corporate social responsibility as a business system that enables the production and distribution of wealth for the betterment of its stakeholders through the implementation and integration of ethical systems and sustainable management practices.

World Business Council of Sustainable Development (1998) ${ }^{[10]}$ has given a definition to CSR, "Continuing commitment by business to contribute to economic development while improving the quality of life of the workforce and their families as well as of the community and society at large." Therefore, to examine and keep developing the corporations, World Business Council targets the realization of the Sustainable Development Goals (SDGs) ${ }^{[11]}$ through six work programs which contain circular economy, cities \& mobility, climate \& energy, food, land and water, people and redefining value to achieve systems transformation.

Countries participated in the conference held by the United Nations in 2000 jointly signed the United Nations Millennium Declaration, promising to make great efforts in The Millennium Development Goals (MDGs) ${ }^{[12]}$ which includes eight international development goals for the year of 2015. All 191 United Nations members stated at that time, and at least 22 international organizations, committed to eradicating extreme poverty and starvation, to achieve universal primary education and ensure environmental sustainability etc. by 2015. Continued in 2016, the 193 countries in the UN adopted "Transforming our World: the 2030 Agenda for Sustainable Development." Sustainable Development Goals (SDGs) ${ }^{[13]}$ are a collection of 17 goals formulated by the United Nations, which urge global enterprises and citizens consider furthermore how to achieve international development and combine with CSR strategies. SDGs are the extension of MDGs that coherent and integrate the agenda in the United Nations after 2015. This can be seen as another big step for corporations to increase their consciousness on CSR and take much more action into practice.

There are plenty of theses discuss with the relationship between CSR and corporate financial performance (CFP), whether there are positively or negatively correlated with CSR, even if there is no relationship with each other. An empirical analysis of Indian banks (Shafat Maqbool \& M. Nasir Zameer, 2018) ${ }^{[14]}$ used a panel data set of 28 Indian commercial banks for 10 years. The empirical analysis took ROE, ROA, net profit, sales profit and price-to-earning ratio as the five performance variables and gave them different weights individually to calculate the profitability and stock market returns. The result shows CSR positively impacts profitability and stock market returns. Based on this kind of thesis, we are eager to acquire more relative information to prove is there any relationship between CSR and CFP.

It has still been questionable about the relationship between CSR and financial performance although plenty researches have committed in this problem. Thus, in our study we try to figure out how to do the financial indicators impact CSR and what kind of relationship do they have either on each other or on together.

\section{Data research}

\subsection{Research hypotheses}

The instrumental stakeholder theory is formed from two theories, and suggests there is a positive relationship between corporate social performance (CSP) and CFP. (Thomas M. Jones, 1995) ${ }^{[15]}$ While there is an abundance of research on CSR and CFP, no study has examined the details of CFP, such as earnings per share and return on stock price and so on. In order to get a far better understanding of the relationship between CSR and CFP, we structure our hypotheses as follows: 
H1: When a company implements CSRs, leverage ratio, sales growth rate and earnings per share have the effect of its return on stock price.

H2: When a company implements CSRs, leverage ratio, sales growth rate and return on stock price have the effect of its earnings per share.

H3: When a company implements CSRs, leverage ratio, sales growth rate and return on equity have the effect of its return on stock price.

H4: When a company implements CSRs, leverage ratio, sales growth rate and return on equity have the effect of its earnings per share.

\subsection{Data collection}

The samples of this study are based on Large Enterprises, Medium-sized Enterprises and Little Giant which are ranked on the 2017 Corporate Citizens list of Common Wealth Magazine ${ }^{[16]}$. Other public companies (TSE-listed) that are not ranked on these three lists are included for comparison but deducted 9 companies which have no complete information in the year of 2017. Thus, there have 934 enterprises in our research. The Taiwan Economic Journal (hereafter, denoted by TEJ) is used to collect fundamental financial data and various ratios of each enterprise. On the basis of TEJ Finance DB and TEJ Stock Price DB, select the dependent variable field and explanatory variable field in the period of 2017.

\subsection{Definition of variables}

\subsubsection{CSR variables}

All enterprises are acquired from the Excellence in CSR list of Common Wealth Magazine in 2017. The number of samples in the Excellence in CSR is set as a dummy variable. For example, companies that listed on the list will be given as 1 ; otherwise, it will be given as 0 . This will enable us to determine whether the implementation of CSRs affects companies' stock prices or operating performance.

\subsubsection{Financial data variables}

1. Earnings per Share (EPS): EPS indicates the profitability of the company, which can be used to measure stock price. High EPS represents high profitability per unit of capital. The calculation is as follows:

EPS $=$ (net profit after tax - preferred share capital)/common share capital

2. Return on Equity (ROE): ROE measures the net profit after tax generated by each shareholder's equity, reflecting whether an enterprise can effectively use shareholders' equity to generate its profitability, which is an important profitability indicator. It is also a ratio that evaluates the operating performance of a company. The calculation is as follows:

$\mathrm{ROE}=$ Income after tax/shareholder's equity

3. Return (RETURN): Annual return rate of individual stocks. The calculation is as follows:

Annual rate of return $=\left[\sum(1+\right.$ daily return rate/100 $\left.)-1\right] \times 100 \%$

4. Leverage (LEV): Leverage is an important ratio that evaluates a company's risks and liabilities level. The smaller of the ratio, the safer of the company. The calculation is as follows:

Leverage $=$ Total liabilities/total assets

5. Sales growth rate (SGR): Sales growth rate indicates how well do the company's sales in this period compare to the previous period. The calculation is as follows:

Sales growth rate $=($ Sales of this year-Sales of the previous year $) /$ Sales of the previous year

\subsection{Research restriction}

The samples of CSRs in the study are selected from the company listed in the Excellence in CSR list in Common Wealth Magazine in 2017. However, the definition of CSR is still be discussed, there is no certain definition of CSR. Every other explanation of CSR might result in a different outcome and could have a different result of a company 
listed on the list. The samples of companies are selected from public companies in Taiwan. However, there might be some companies that are listed in the Excellence in Corporate Social Responsibility list but they are a private company.

\subsection{Empirical analysis}

Model setting

The study is divided into four different regression models, using EPS and annual return on stock (RETURN) to evaluate corporation performance and stock returns. Other major variables include CSR, financial leverage (LEV), operating income growth rate (SGR), earnings per share (EPS), return on equity (ROE), and annual return on stock (RETURN). The symbol $\varepsilon$ follows the standard normal distribution with mean 0 and standard deviation 1 . As a result, the four types of designed models are formally given by the following:

RETURN $=\alpha+\beta_{1} \mathrm{CSR}+\beta_{2} \mathrm{LEV}+\beta_{3} \mathrm{SGR}+\beta_{4} \mathrm{EPS}+\varepsilon$

$\mathrm{EPS}=\alpha+\beta_{1} \mathrm{CSR}+\beta_{2} \mathrm{LEV}+\beta_{3} \mathrm{SGR}+\beta_{4} \mathrm{RETURN}+\mathcal{\varepsilon}$

RETURN $=\alpha+\beta_{1} \mathrm{CSR}+\beta_{2} \mathrm{LEV}+\beta_{3} \mathrm{SGR}+\beta_{4} \mathrm{ROE}+\mathcal{E}$

$\mathrm{EPS}=\alpha+\beta_{1} \mathrm{CSR}+\beta_{2} \mathrm{LEV}+\beta_{3} \mathrm{SGR}+\beta_{4} \mathrm{ROE}+\mathcal{E}$

\subsection{Descriptive statistics}

The attended value of this study is 934 datasets. The basic statistics of variables are shown in the following Table $\mathbf{1}$ as follows:

\begin{tabular}{|l|l|l|l|l|l|}
\hline & Sample Size & Mean & $\begin{array}{l}\text { Standard Devia- } \\
\text { tion }\end{array}$ & Minimum & Maximum \\
\hline CSR & 934 & 0.0599 & 0.2374 & 0 & 1 \\
\hline RETURN & 934 & 25.7498 & 48.6542 & -77.93 & 490.01 \\
\hline LEV & 934 & 44.6850 & 20.3703 & 0.97 & 99.76 \\
\hline SGR & 934 & 8.2526 & 48.6684 & -97.06 & 765.05 \\
\hline EPS & 934 & 2.4677 & 7.3102 & -20.58 & 193.65 \\
\hline ROE & 934 & 5.4856 & 22.9311 & -385.56 & 69.68 \\
\hline
\end{tabular}

Table 1. The basic statistics of variables

\subsection{Estimated results}

\section{Impact of CSR on RETURN}

\begin{tabular}{|l|l|l|l|}
\hline & Regression coefficients & t-value & p-value \\
\hline RETURN & -0.054 & -1.658 & $0.098^{*}$ \\
\hline LEV & 0.000 & -0.011 & 0.991 \\
\hline SGR & 0.170 & 5.264 & $0.000^{* * *}$ \\
\hline EPS & 0.064 & 1.966 & $0.050^{*}$ \\
\hline
\end{tabular}

Note: Superscripts $* * *, * *$, and $*$ indicate statistical significance at the $0.01,0.05$, and 0.10 level, respectively.

\section{Table 2. Impact of CSR on RETURN}

Table 2 presents that CSR, LEV and EPS are not significantly correlated with RETURN; SGR is significantly positively correlated. At a p-value $<0.01$, the regression ratio of SGR to RETURN is 0.170 ( $\mathrm{t}$-value $=5.264$ ), thereby indicating a significantly positive correlation. SGR shows ability to sales of a company. When a business has a positive SGR, the business may flourish steadily. Firmly growing company has a better return on its stock value. CSR does not have a significant correlation with the regression coefficient of RETURN of -0.054 ( $\mathrm{t}$-value $=-1.658$ ). 


\section{Impact of CSR on EPS}

\begin{tabular}{|l|l|l|l|}
\hline EPS & Regression coefficients & t-value & p-value \\
\hline CSR & 0.096 & 2.934 & $0.003^{* *}$ \\
\hline LEV & -0.098 & -2.977 & $0.003^{* *}$ \\
\hline SGR & 0.045 & 1.377 & 0.169 \\
\hline RETURN & 0.065 & 1.966 & $0.050^{*}$ \\
\hline
\end{tabular}

Note: Superscripts $* * *, * *$, and $*$ indicate statistical significance at the $0.01,0.05$, and 0.10 level, respectively.

Table 3. Impact of CSR on EPS

Table 3 shows that CSR and LEV are significantly positively correlated with EPS; SGR and RETURN are not significantly correlated with EPS. At a p-value $<0.01$, CSR has a significantly positive correlation with the regression coefficient on EPS of 0.096 (t-value = 2.934), and LEV has a significantly negative correlation with the regression coefficient on EPS of -0.098 ( $\mathrm{t}$-value = -2.997). A company does CSR are having higher EPS which stands for net income divided from the weighted average number of ordinary shares outstanding. When a company has higher net income represent it has the capability to do and do well on CSR. On the other hand, when a company has higher EPS, it will perform lower financial leverage which stands for a company that has smaller liabilities against the asset. As is acknowledged, the companies which do CSR acquire better performance on EPS that shareholders highly anticipated and receive a reverse trend on financial leverage that implicit the companies are relatively steady.

3. Impact of CSR on RETURN

\begin{tabular}{|l|l|l|l|}
\hline RETURN & Regression coefficients & t-value & p-value \\
\hline CSR & -0.061 & -1.891 & $0.059^{*}$ \\
\hline LEV & 0.018 & 0.552 & 0.581 \\
\hline SGR & 0.157 & 4.849 & $0.000^{* * *}$ \\
\hline ROE & 0.130 & 3.949 & $0.000^{* * *}$ \\
\hline
\end{tabular}

Note: Superscripts $* * *, * *$, and $*$ indicate statistical significance at the $0.01,0.05$, and 0.10 level, respectively.

Table 4. Impact of CSR on RETURN

Table 4 shows that SGR and ROE are positively correlated and significant. With a p-value $<0.01$, the regression coefficient of SGR to RETURN is 0.157 ( $\mathrm{t}$-value $=4.849$ ), thereby indicating a significantly positive correlation, and the regression coefficient of ROE to RETURN is 0.130 ( $\mathrm{t}$-value $=3.949$ ), thereby indicating significantly positive correlation. In addition, the regression coefficient of LEV to RETURN is 0.018 (t-value $=0.552$ ), thereby indicating positive correlation. CSR has negative correlation with the regression coefficient of RETURN of $-0.061(\mathrm{t}$-value $=-1.891)$. However, the coefficients of CSR and LEV are not significant at the 0.05 level. Table 4 provides that SGR and ROE are positive for RETURN; thus, SGR and ROE have a positive impact on RETURN. However, Table 4 shows that CSR is not significant for RETURN; thus, CSR has no significant impact on RETURN.

4. Impact of CSR on EPS

\begin{tabular}{|l|l|l|l|}
\hline EPS & Regression coefficients & t-value & p-value \\
\hline CSR & 0.067 & 2.094 & $0.037^{* *}$ \\
\hline LEV & -0.049 & -1.524 & 0.128 \\
\hline SGR & 0.023 & 0.728 & 0.467 \\
\hline
\end{tabular}




\begin{tabular}{|l|l|l|l|}
\hline ROE & 0.258 & 7.981 & $0.000^{* * *}$ \\
\hline
\end{tabular}

Note: Superscripts $* * *, * *$, and $*$ indicate statistical significance at the $0.01,0.05$, and 0.10 level, respectively.

Table 5. Impact of CSR on EPS

Table 5 shows that ROE and CSR are positively correlated and significant, hence, indicating companies that implement CSRs have better performance over those do not implement CSRs. With a p-value $<0.05$, the regression coefficient of ROE to EPS is 0.258 ( $\mathrm{t}$-value $=7.981$ ), thereby indicating a significantly positive correlation, and the regression coefficient of CSR to EPS is 0.067 (t-value = 2.094), thus representing significantly positive correlation. The regression coefficient of LEV to EPS is -0.049 ( $\mathrm{t}$-value $=-1.524$ ), indicating negatively correlation. SGR has a positive correlation with the regression coefficient of EPS of 0.023 (t-value = 0.728). Nevertheless, the coefficients of LEV and SGR are not significant at the 0.05 level. Table 5 indicates that CSR is significantly and positively related to EPS. Therefore, return on equity and CSR have a positive impact on companies' EPS. While LEV is negatively correlated with EPS, SGR is positively yet not significantly correlated with EPS.

\section{Conclusion}

Empirical results of this study show that the EPS of the companies that implement CSRs are better than those that do not implement CSRs. However, the results do not indicate that the RETURN of the companies that implement CSRs is better than those that do not implement CSRs. That is to say, implementing CSRs increases companies' EPS, so companies' profitability and corporate performance will be significantly higher. These results are partially consistent with the hypotheses of this study. Evidence means that when companies investing in various social welfare activities and fulfilling their social obligations, it will bring more profit to company, which results in a higher EPS. However, implementing CSRs does not represent companies will have a better stock price. The stock price is affected by not just CSRs but other factors such as international or domestic financial events. CSR is the cause that will affect stock price but not the only factor that affects the stock price.

\section{Acknowledgements}

The authors thank the anonymous referees for comments and suggestions. Yu-Min Lian is grateful for the funding support from the Ministry of Science and Technology under grant MOST107-2410-H-030-020.

\section{References}

1. Archie B. Carroll. A history of corporate social responsibility: Concepts and practices. In Andrew Crane, Abigail McWilliams, Dirk Matten, Jeremy Moon \& Donald Siegel (eds.) The Oxford Handbook of Corporate Social Responsibility. Oxford University Press, 19-46; 2008.

2. respACT Austria. Sondernummer July; 2006.

3. N. Craig Smith. Corporate social responsibility: Not whether, but how? Centre for Marketing Working Paper. No. 03-701. April; 2003.

4. Nick Lin-Hi, Karsten Müller. The CSR bottom line: Preventing corporate social irresponsibility. Journal of Business Research 66, 1928-1936; 2013.

5. Andrew Crane \& Dirk Matten. Corporate social responsibility as a field of scholarship; 2007.

6. Howard Bowen. Social responsibilities of the businessman. New York: Harper \& Row; 1953.

7. Milton Friedman, Rose D Friedman. Capitalism and freedom. Chicago: University of Chicago Press; 1962.

8. Milton Friedman (editor). Time magazine. New York: Time Inc.; 1969-12.

9. Smith, Richard E. Defining corporate social responsibility: A systems approach for socially responsible capitalism. Master of Philosophy Theses. 9; 2011.

10. World Business Council for Sustainable Development Corporation Social Responsibilities definition [Internet]. (1998). Available from: https://growthorientedsustainableentrepreneurship.files.wordpress.com/2016/07/csr-wbcsd-csr-primer.pdf

11. World Business Council's Sustainable Development Goals (SDGs) [Internet]. Available from: https://www.wbcsd.org/

12. The Millennium Development Goals [Internet]. Available from: http://www.un.org/millenniumgoals/

13. The 2030 Agenda for Sustainable Development's Sustainable Development Goals (SDGs) [Internet]. Available from: https://www.un.org/sustainabledevelopment/development-agenda/

14. Shafat Maqbool, M. Nasir Zameer. Corporate social responsibility and financial performance: An empirical analysis of Indian banks. Future Business Journal, Vol.4, Issue 1, pp. 84-93; June, 2018. 
15. Thomas M. Jones. Instrumental Stakeholder Theory: A Synthesis of Ethics and Economics. The Academy of Management Review, Vol. 20, No. 2, pp. 404-437; Apr., 1995.

16. Common Wealth Magazine [Internet]. Available from: http://topic.cw.com.tw/csr/report.aspx 